The answer to the second part of the question is that it depends on the "out-patient department." Treatment as suggested above? Certainly not. The week-in, week-out dressing of chronic sinuses? Certainly not, for this is not treatment of the disease. Treatment as part of a planned programme may have some place in an out-patient department if the department is such that complete surgical precautions are followed. Too often cases of chronic osteitis are regarded as dirty problems which cannot be made dirtier-let alone the impunity with which such cases are treated alongside cases of industrial injuries to the hand, burns, and other wounds.

\section{Treatment of Empyema}

Q.-What is the accepted treatment for acute and chronic empyema? When is rib-resection performed?

A.-A full answer to this question would require a volume. Treatment of acute empyema varies greatly according to the causative organism, the presence of accompanying lesions in the lung and elsewhere, and anatomical aspects. The exact place of penicillin in the treatment of acute empyema has still to be determined. With all these variable factors there is no one "accepted treatment" for empyema, and it is impossible in a short answer to deal in any useful way with the first part of this question.

With regard to the second part-in acute empyema ribresection is indicated only when the collection of pus is localized by pleural adhesions, which will generally be the case if the pus has become thick. While the pus is thin and there is no evidence of adequate pleural adhesions ("pyrothorax" rather than localized "empyema"), the pus must be removed by aspiration or by intercostal drainage. Drainage by a closed method may be indicated even after rib-resection. The most important part of the treatment is to secure complete re-expansion of the lung. This is helped by the early application of suitable active inspiratory breathing exercises. The tube should not be removed from a drained empyema so long as there is evidence that any residual empyema space remains ; and if there is any doubt about this it is well to outline the sinus and residual space, if any, with iodized oil and take radiographs before deciding about removal of the tube. Recently some success has been reported in the treatment of acute empyema caused by penicillin-sensitive organisms by aspiration and injection of penicillin until the pus becomes thick, followed by intercostal drainage, which is used as a method of continuing the intermittent aspirations and injections of penicillin. The exact place of this line of treatment has still to be determined. With regard to chronic empyema it should be realized, first, that many such empyemata are the result of inadequate treatment of acute empyema. In any case of chronic empyema the diagnosis is not complete until the underlying disease, especially tuberculosis, new-growth, and chronic suppurative processes in the lung, has been considered. The diagnosis of chronic simple empyema having been thus established the first step is to secure free drainage by adequate rib-resection. Suction drainage, breathing exercises, and, unless there is a pleuro-bronchial fistula, irrigation of the cavity should then be instituted. If this does not result in obliteration of the empyema space plastic operations on the chest wall, combined in resistant cases with one of the several special surgical techniques for mobilization of the thickened parietal pleura, will become necessary.

\section{Sequelae of Encephalitis Lethargica}

Q.-Is there any effective treatment for chronic encephalitis lethargica? Have penicillin, the sulphonamides, fever therapy, protein shock, or repeated lumbar punctures any proved value in the treatment of this condition?

A.-Penicillin and the sulphonamides are of no value in the treatment of chronic encephalitis lethargica. There is no reason to suppose that repeated lumbar puncture would be helpful. Artificial pyrexia, most simply induced by the intravenous injection of T.A.B. or $B$. coli vaccine, has a limited value, especially for encephalitic parkinsonism, when the disorder is not too far advanced.

\section{LETTERS, NOTES, ETC. \\ Medical Service in Australia}

Sir Ernest Graham-Little, M.P., writes: Dr. Gilliland quotes a letter from the High Commissioner of Australia received by the Medical World, the organ of the Medical Practitioners' Union, containing the statement: " No Bill to establish a State medical service has been introduced into the Commonweaith Parliament of Australia " (B.M.J., Sept. 14, p. 407). Dr. Gilliland declares that this " contradiction " "calis for explanation from me," and I hope you will allow me to supply it. The information from my correspondent in Canberra upon which I based my letter (B.M.J., Aug. 24) was to the effect that an Act containing proposals for State-provided and partially State-controlled medical services was passed some years ago by the Socialist Government in Australia; that the medical profession in Australia, regarding these proposals as a threat to their freedom, refused to accept service under the Act and that consequently it has not been put into operation up to the present date. One would like to see the letter from the M.P.U. (a consistent advocate of State service) that elicited the above very guarded reply which, it is to be noted, does not " contradict" my statements but merely repudiates a description (which nobody offered) of that Act as "establishing a State medical service." (Fortunately, as the Minister of Health, confronted with the Australian revolt, realized, one cannot establish a State medical service without the consent of the doctors.) I have not seen the text of the Australian Act and I am writing to Canberra asking to be furnished with a copy, but from my correspondent's description it would seem to present a general resemblance to Mr. Bevan's Bill. A State service postulates national full-time salaried pensionable medical personnel which has been the declared goal of the Socialists for more than a decade. (See Hansard, May 1, Col. 225.) Mr. Bevan's Bill goes a very long way towards achieving this aim: he prudently forbears for the moment to go all the way, but he has not forgone the hope and expectation that this aim will be achieved when, as he expressed it in the debate, the time is "ripe" for that ultimate complete fulfilment. It is significant that a motion to introduce such a service in Britain was proposed to the Representative Body in 1943 and was rejected by a twenty-to-one majority at a meeting attended by practically the entire membership of that body: their verdict has been repeated on several occasions since that date. It is clear that our Australian colleagues saw in the Act which they rejected a similar threat to their freedom, and I submit their example is one which we might well follow now.

\section{Varicose Ukers and Penicillin}

Dr. W. T. E. Blackmore (Abergavenny) writes: A reference in Letters, Notes, etc., in the Journal of Aug. 17 (p. 252) prompts me to relate my experience of the value of penicillin cream in the treatment of varicose ulcers. Thirty-two varicose ulcers, with penicillinsensitive organisms, have been successfully treated during the last ten months by adopting the following technique. After thorough cleansing with warm saline a dressing of penicillin cream $(100,000$ units to 1 oz. ( $(30$ g.) $)$ is applied on a gauze pad. The entire lower leg-foot to knee-is then firmly bandaged with a supporting bandage of the Unna type and a second thin gauze bandage applied over it. This is left in position for a week, the patient being advised to pursue in the meantime his or her normal activities; then the dressing is renewed. The average length of treatment is seven to eight weeks, that is, seven or eight dressings; after which the ulcer is firmly healed; and treatment of the underlying cause is then carried out. One case, which took tweive weeks to clear, was a varicose ulcer some 6 by $2 \frac{1}{2}$ in. $(15$ by $6.4 \mathrm{~cm}$.); so one is entitled to assume that this form of treatment is of definite value.

\section{An Offer of Medical Equipment}

A medical man in the South of England informs us that the doctor son of one of his patients was killed in Burma. The father has a sphygmomanometer, an electric ophthalmoscope, and an auriscope; also one or two oddments. He would like to give these to a doctor who has lost his equipment by reason of war, or to a doctor returning from the Forces and in need of professional apparatus. Letters addressed to this office will be forwarded.

\section{Corrections}

We apologize for the oversight by which the words " encephalitis " and "encephalopathy" were misprinted in the footnote to Dr. C. E. S. Harris's letter last week (p. 442).

The word "undermined" should have read "underlined" in Dr. Anthony C. Hamer's letter published under " Tobacco and Ulcer Dyspepsia" in the Journal of Sept. 14, p. 402.

A misprint occurred in Fl.-Lieut. W. P. U. Jackson's letter (Sept. 14, p. 403). The word " trend" in the first sentence should of course be " triad," and the clause should run ". . . the triad of symptoms, polyarthritis, urethritis, and conjunctivitis noted in my article (Aug. 10 , p. 197) as being characteristic of Reiter's disease may. also be associated with bacillary dysentery." 